\title{
The Effect of Operational Cutting Parameters on Nitinol-60 in Wire Electrodischarge Machining
}

\author{
Ali Akbar LotfiNeyestanak ${ }^{1}$ and Saeed Daneshmand ${ }^{2}$ \\ ${ }^{1}$ Department of Mechanical and Aerospace Engineering, Science and Research Branch, Islamic Azad University, Tehran, Iran \\ ${ }^{2}$ Department of Mechanical Engineering, Majlesi Branch, Islamic Azad University, Isfahan 86316-56451, Iran \\ Correspondence should be addressed to Saeed Daneshmand; s.daneshmand@iaumajlesi.ac.ir
}

Received 12 January 2013; Accepted 31 January 2013

Academic Editor: S. Miyazaki

Copyright (c) 2013 A. A. LotfiNeyestanak and S. Daneshmand. This is an open access article distributed under the Creative Commons Attribution License, which permits unrestricted use, distribution, and reproduction in any medium, provided the original work is properly cited.

\begin{abstract}
Shape memory alloys are a kind of active materials, which have significant characteristics in comparison with other alloys. Since these materials are applicable in different fields such as aerospace, automobile industry, medicine, and dentistry, the effects of wire electrodischarge machining on the properties of these alloys have been studied. In this paper, changes in the shape recovery ability and microhardness of the machined surface of Nitonol-60 shape memory alloy have been studied considering recasting and formation of resolidificated layer on the shape memory alloy surface. XRD and EDXA analyses of the surface layer of the sample besides a microscopic study of the shape memory alloy layer by SEM and a study of the changes in mechanical properties of the surface layer were done by performing microhardness and tension tests on the work piece surface. Considering the surface layer, reversible strain has been studied according to the shape recovery percentage of Nitinol-60 shape memory alloy. Results show that the surface layer formed on the surface of the samples has caused changes in both physical and mechanical properties of the cut surface because of the penetration of the separated materials in comparison with deeper layers of the piece.
\end{abstract}

\section{Introduction}

Shape memory alloys can respond properly to the environmental changes and adjust themselves in the best way. These alloys are applied in industries like medicine, dentistry, aerospace, automobile industry, electronic industry, and so forth. Shape memory alloys show some new and special characteristics such as sensibility, high damping, adaptive responses, memorized capability, and superelasticity which can be used in engineering equipments for intelligent systems. Shape memory alloys are a type of materials with a significant memorability. If a small percentage of deformation occurs on a shape memory alloy with determined chemical composition and it is heated above its deformation temperature, the alloy can recover its original shape. Deformation temperature is the phase transformation temperature of austenite to martensite and vice versa. These two phases have totally different characteristics [1]. Nitinol is one of the most significant intermetal binary combinations. NickelTitanium is the most important combination of smart alloys and includes special properties which differentiate it from other materials including other intermetal compounds $[2$, 3]. In addition to specific mechanical properties such as high strength and hardness, Nitinol-60 has high thermal and electrical conductivity. These characteristics of Nitinol made it applicable in medical equipments and producing lots of mechanical components. This alloy is nonmagnetic like silicon nitride and has high electrical conductivity [46]. The main reason of superelasticity and memorability is a reversible martensite transformation in solid phase. Unique behavior of Nitinol, according to phase transformation, depends on the temperature of austenite to martensite in atomic scale. Because of the chemical composition of Nitinol shape memory alloy, it can remain in martensite phase in lower temperature and in austenite phase in higher temperature. Many properties of Nitinol in these two phases are completely different with each other [7]. By using the superelastic or one-way memory properties of Nitinol, for special applications, appropriately molding Nitinol is needed. Then a special heat treatment will be done to reach the final form. 


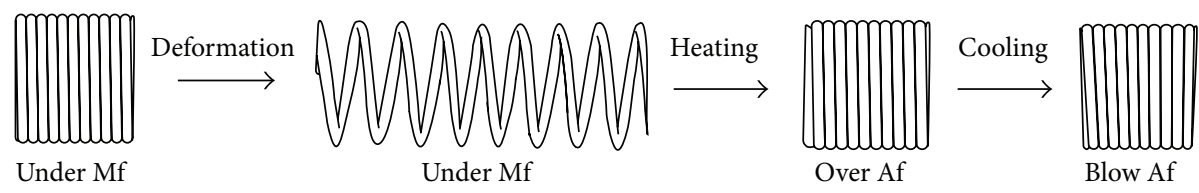

(a) OWSM

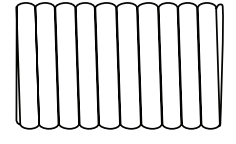

Under Mf

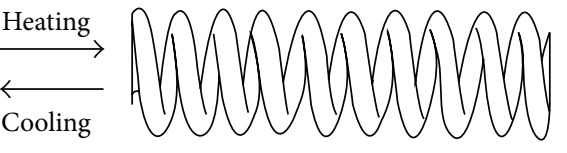

Over Af

(b) TWSM

FIgURE 1: Two instructions of two-way memory training [1].

The mentioned heat treatment is similar in both superelastic and shape memory properties of Nitinol. The effective parameters of heat treatment (temperature and sufficient time) are needed for coordinating the shape and piece properties. These parameters are usually derived experimentally for each piece. Some cooling methods like quenching in water or fast cooling in air are preferable [8]. Two procedures (One-Way Shape Memory (OWSM) and Two-Way Shape Memory (TWSM)) can be used for training two-side memory. In OWSM, the sample is cooling below the Mf temperature and is formed properly (Figure 1). Then it heats above the Af temperature till it gets its austenitic shape. It is necessary to repeat the method 20 to 30 times to be done completely. So the sample will obtain the planned shape by cooling below the Mf and will take any other shape by heating above Af. In TWSM, the sample is bent exactly above the Ms temperature to produce martensite reference variables obtained by stress and then it is cooled up to the temperatures below Mf. With following heating up to the temperature above Af, the sample will get its original austenitic shape [1].

Nowadays wire electrodischarge machining (WEDM) with a significant improvement is the prior method in cutting the metals especially to produce complex pieces with high accuracy and precision [9]. Since conventional machinery mostly is not quite effective in some industries, in particular, space industry by using new materials (especially shape memory alloys, superalloys, and really expensive and superhard materials), WEDM can be qualified enough to respond to these needs. It is a method with less superfluity that makes it so economical with high precision in cutting the irregular shapes [10]. By the increasing improvement in applying shape memory alloys especially applying Nitinol alloy in different industries and also by taking into account that machining of smart materials with conventional techniques is a difficult way of cutting because of the high malleability, the extensive hard work, and reducing the quality of work piece that results in equipment depreciation in addition to that little precision and speed of machining cause undesirable effects on the properties of the surface of materials, the study of new machining methods like WEDM as one of the best choices in industry and also the study of the effects of these methods on surface properties of smart alloys seem necessary. By eliminating its inefficiency and problems, it would be possible to achieve more precision and accuracy besides the maximum work speed [11-14]. Chip sampling by electric discharge is an electrothermal process considering heat and electricity [15]. Material removal from the work piece in WEDM is done by making a pulse and interrupted voltage between two electrodes, a wire, and a work piece which are floated in deionized water as dielectric, by means of sparking along the channel between the electrodes [16, 17]. With each spark a small part of the material separates from the work piece surface and a smaller part from the wire surface (considering its small size, it is called debris). Finally, with a large number of sparks machining will be done $[10,15]$. In this method, material removal is based on the erosion effect of electric sparks so that the thermoelectric theory is the most assured model. Since high temperature produces high density of energy on the surface, this theory leads to melting, evaporating, and forming small basin and carters at the work piece surface $[18,19]$. After the burst of the gas bubble and removing pressure from the melted basin formed on the surface of the work piece and wire, the particles of the wire electrode exit from the basin formed by sparks with high velocity and start to move rapidly at random by removing the pressure plasma column and colliding to the body of the work piece (Figure 2) $[18,20]$. Therefore, alloying is done at the cutting surface by recasting materials of background and mixing the alloy elements with the background.

During the alloying in the melted basin, a quick displacement current forms which results in redistribution of alloy elements in this region. At the cutting surface, a layer with a thickness of $20-50 \mu \mathrm{m}$ will be formed so that if the alloy layer is rich in alloy elements it will have better properties than the background. In this case, surface roughness is more than the first state. Surface roughness largely depends on a homogenous mixture of alloy elements in the melted basin. Also this homogenous mixture depends on mass displacement in the melted basin. A thin penetrable layer with a thickness of $10 \mu \mathrm{m}$ is formed in the boundary of the melted basin and background. This phenomenon occurs because of the penetration of narrow melted channels in the grain boundaries [21]. 


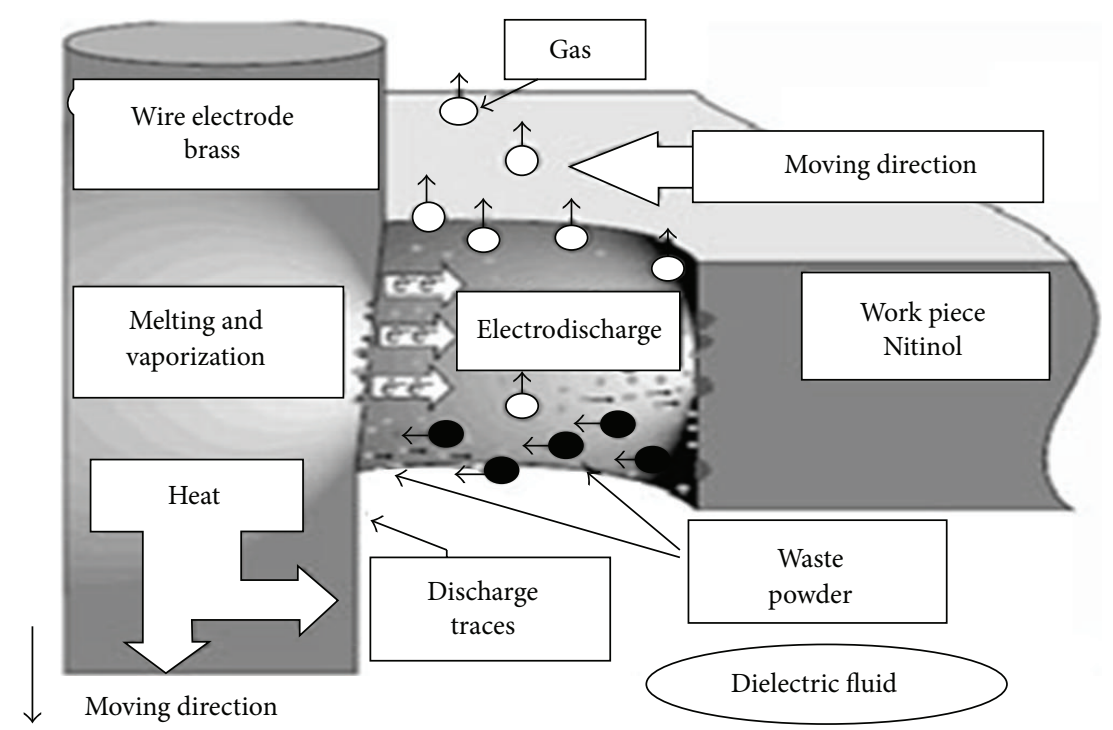

(a) Wire and work piece erosion during the material removal process

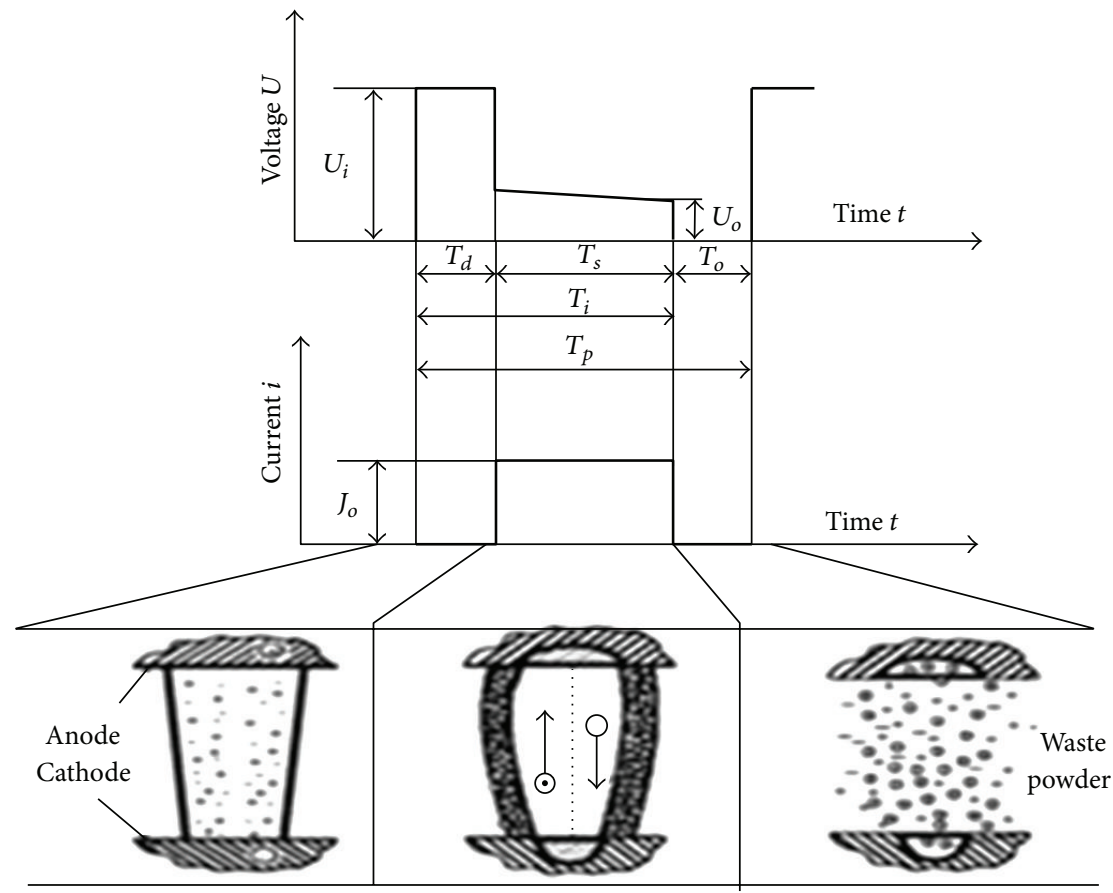

(b) Craters formed on the wire

FIGURE 2: Schematic image of machining process with WEDM.

\section{Materials and Attitude}

In this study, test samples were prepared by using Nickel and Titanium with commercial purity according to general requirements of the standard F2063-00 [22] and molded by the melting process under vacuum condition in the vacuum induction melting (VIM) at $1400^{\circ} \mathrm{C}$ and in a Calcia $(\mathrm{CaO})$ melting pot, and then they were subjected to cold rolling. Finally, annealing was performed on these samples [23, 24]. Machining of prepared samples was done with WEDM-Agie 15. For unifying the work throughout all the experiments of Nitinol-60 alloy piece, which is under machining, an alloy with similar analysis and a molded piece in a same condition were used. Moreover, a wire electrode with a fixed alloy percentage of $\mathrm{CuZn} 37$ and fixed diameter of $0.25 \mu \mathrm{m}$ was used. On the other hand, considering the effects of electrical conductivity of dielectric, this amount did not change during the experiments by controlling the amount of electrical conductivity of d-ionized water and samples dried immediately after cutting to avoid oxidation at the sample surface. Then they were studied with the purpose of surface morphology by scanning electron microscope (SEM). 


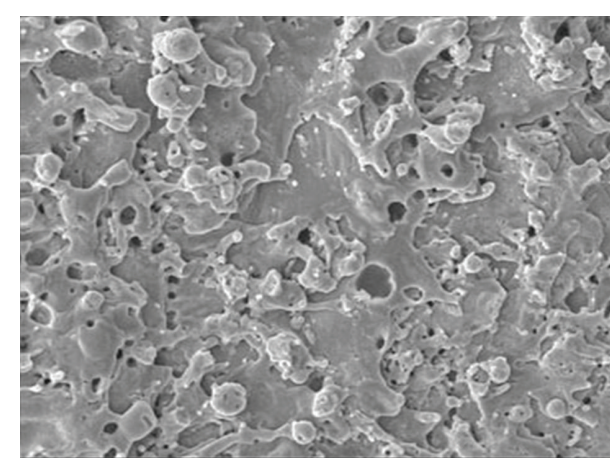

(a) Cutting surface with a magnification of $1500 \mathrm{x}$

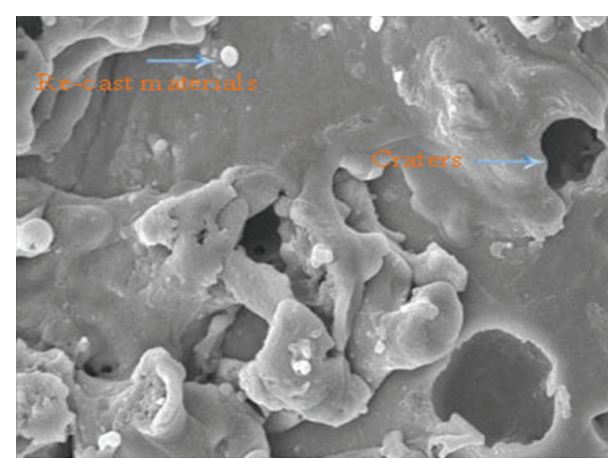

(b) Cutting surface with a magnification of $5000 \mathrm{x}$

FIGURE 3: SEM images of Nitinol-60 cut surface with WEDM.

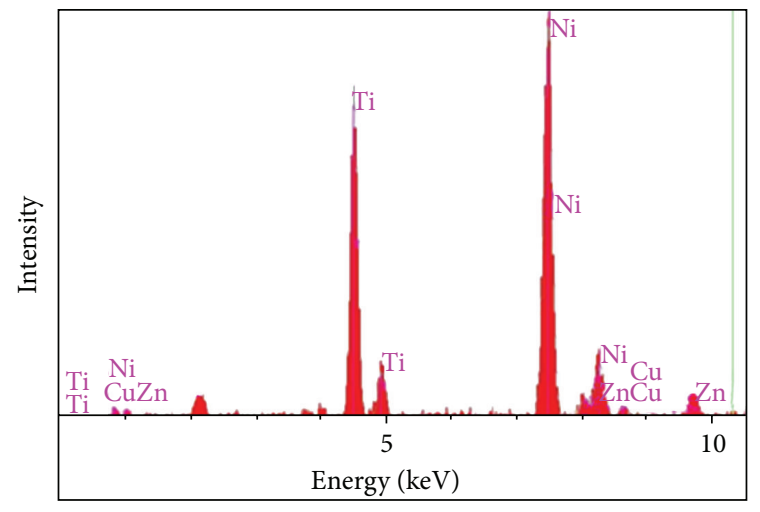

(a) Before cutting

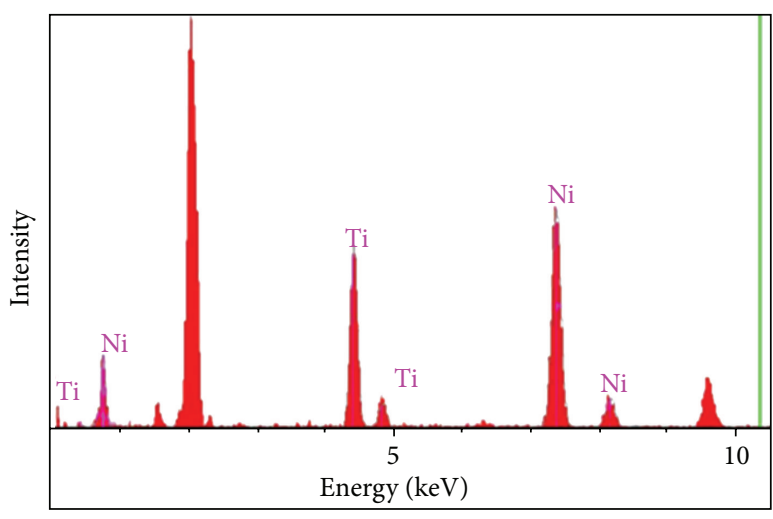

(b) After cutting

FIGURE 4: EDXA analysis of Nitinol-60.

In addition, XRD and EDXA analyses were used for studying the alloy layer formed on the work piece surface and phase and alloy changes because of the penetration of wire materials on the work piece surface. The hardness of the sample surface was obtained by microhardness system MH1 with a mass of $2 \mathrm{~kg}$ in a period of $20 \mathrm{~s}$. In this experiment, for each sample, the average hardness was reached by performing 5 tests on different parts of the surface. At last for studying the effect of the surface layer, which formed on the work piece surface, on the shape recovery percentage of Nitinol shape memory alloy after cutting with WEDM, a tension test with different strain percentages from $1 \%$ to $11 \%$ were carried out on the cut samples. For comparing, the tension test was done on the samples which were only under the molding and cold rolling operations.

\section{Results and Discussions}

3.1. Morphology and Chemical Analysis of Cutting Surface of Nitinol Alloy with WEDM. In this part of laboratory research, cut surface of Nitinol alloy with WEDM was studied qualitatively and quantitatively considering spark behavior and formation of carters on the work piece surface. Therefore
Nitinol-60 alloy surface which is obtained by cutting under electronic microscope (SEM) and different X-ray analyses (EDXA, XRD) was studied.

Carters form on the surface which is produced by Nitinol60 cutting at the minimum distance between two electrodes (wire and Nitinol alloy) due to the sparks in the electrode gap. The size of the carters and dome-shaped margins that are seen as rims around these carters is quite distinct considering selective operating parameters. SEM images of Nitinol cutting surface show the carters and resolidified layers (Figure 3). By doing spot analysis (EDXA) on the Nitinol cut surface there is a great percentage of $\mathrm{Zn}$ and $\mathrm{Cu}$ besides principal elements like $\mathrm{Ni}$ and $\mathrm{Ti}$ on the work piece surface by taking into account the WEDM process, material removal model with vaporizing, and formation of very small debris and penetration of wire materials by means of the debris. According to the surface morphology of Nitinol, this matter is shown by EDXA analysis of Nitinol cut surface in comparison with the analysis related to Nitinol before cutting by CuZn37 wire. Piece surface analysis before and after cutting by CuZn37 wire is given in Figure 4; in addition, penetration of wire materials on the work piece surface is obviously seen. So considering the size and number of carters or in other words according to the percentage of the debris 


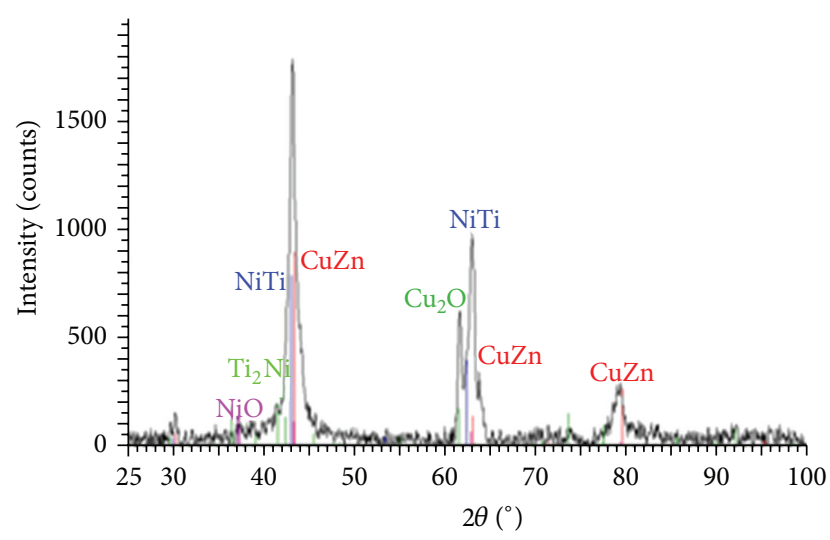

FIgURE 5: XRD analysis of Nitinol-60 cut surface with WEDM.

taken from work piece and wire surfaces, it is important to notice that the debris which reaches the work piece surface with high velocity is not similar in different parameters. It can be also justified in this way that, by successive sparks in a short time, overlap occurs for the carters. Therefore, the increasing in the percentage of the debris, which is separated from wire by vaporizing, causes increasing in the debris concentration in the electrolyte and it will result in an increase of $\mathrm{Zn}$ and $\mathrm{Cu}$ on the Nitinol cut surface. By vaporizing the WEDM wire, alloy elements of wire separate from it as very small spherical substances and penetrate to the Nitinol cut surface which causes phase changes on the cut surface in comparison with base Nitinol metal. So by alloying on the work piece surface, the alloy of surface layer will be different from Nitinol base alloy.

The results of XRD analysis of Nitinol cut surface show the surface phases (Figure 5), and besides Nitinol there are other phases like $\mathrm{CuZn}$, Ti2Ni intermetal compound, and $\mathrm{NiO}$ and $\mathrm{Cu}_{2} \mathrm{O}$ metal oxides. The existence of these compounds causes changes in physical and mechanical properties of the cut surface compared with the depth of the piece.

3.2. Microhardness from Cutting Surface to the Depth of the Alloy Layer Formed on the Cutting Surface. Considering the alloy layer formed and solidificated on the cutting surface with a thickness of less than $20 \mu \mathrm{m}$, to study changes in mechanical properties at the depth of the piece microhardness was measured on the cross-section of Nitinol alloy up to the depth of $250 \mu \mathrm{m}$. The result is shown as a curve in Figure 6, and according to this figure microhardness increases several times on the surface and at the depth of $20 \mu \mathrm{m}$ compared with the microhardness of the piece before cutting due to rapid cooling of recast layer by machining with spraying dielectric water and alloying on the cutting surface. By the increasing in alloy elements such as $\mathrm{Cu}$ and $\mathrm{Zn}$ on the surface and rapid solidification of alloy layer formed by flushing of d-ionized water, superficial layer of cut surface has higher hardness than the base piece considering extremely high solidification speed of a few microseconds.

3.3. Percentage of Reversible Strain. Chemical analysis of alloy layer formed and solidificated on the cut surface (with

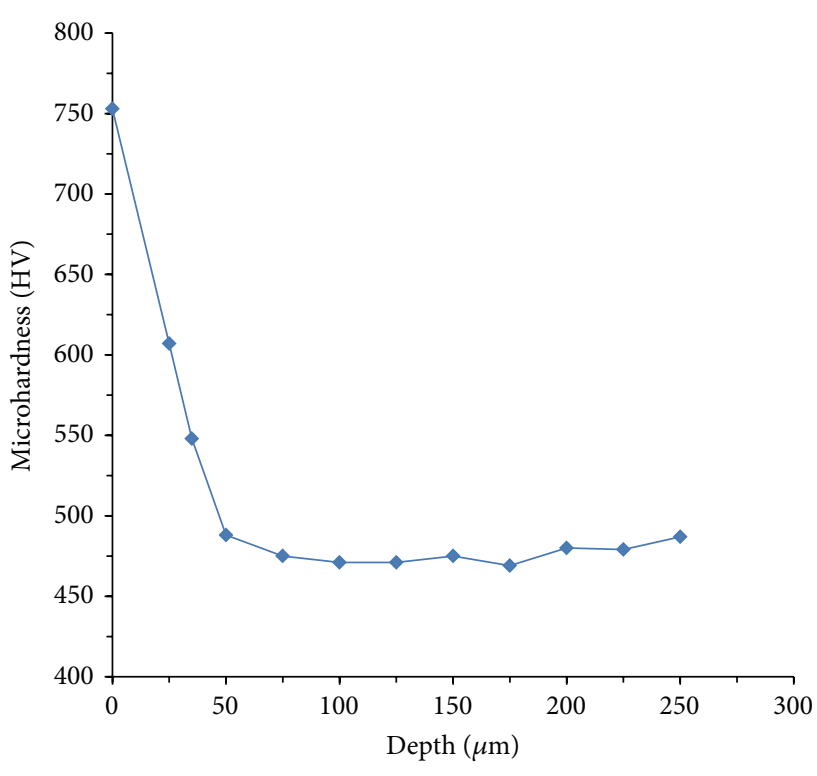

FIgURE 6: Microhardness in different distances of Nitinol-60 cut surface (with WEDM).

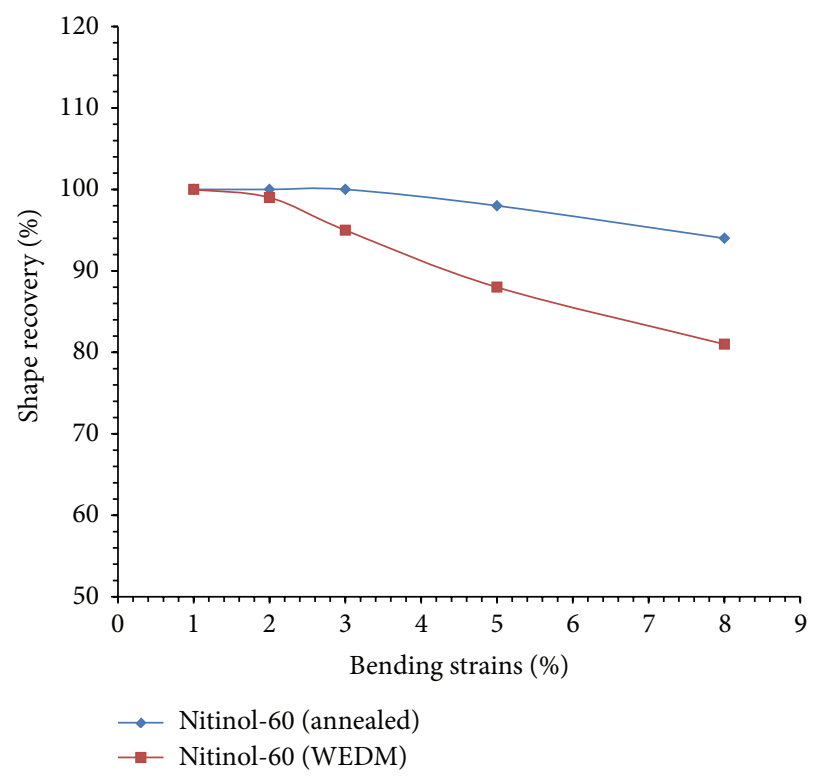

Figure 7: Mechanical properties of Nitinol alloy.

WEDM) with a thickness of $20 \mu \mathrm{m}$ is different from that of Nitinol-60 alloy. Moreover, as shown in Figure 5, the phases of the mentioned surfaces are not the same so according to Figure 7 the mechanical properties of Nitinol cut alloy (with WEDM) and a molded piece which is annealed after cold rolling are obviously different.

\section{Conclusion}

Our research on the cut surface of Nitinol shape memory alloy by WEDM came to the following conclusions. 
(1) Since the cutting procedure by WEDM is an electrothermal process, numerous sparks on the Nitinol60 cut surface lead to forming many carters on the surface of this shape memory alloy and alloying will be done by surface recasting with the penetration of the materials which are separated from WEDM wire into these carters. A layer with a thickness of 10-20 $\mu \mathrm{m}$ will be formed on Nitinol surface by fast cooling of cast surface so this alloy is not Nitinol60 anymore and it includes different phases such as $\mathrm{CuZn}$, Ti2Ni intermetal combination, and $\mathrm{NiO}$ and $\mathrm{Cu}_{2} \mathrm{O}$ metal oxides. For this reason, the existence of these combinations causes physical and mechanical changes on the cut surface in comparison with the depth of the piece.

(2) Microhardness on the Nitinol-60 cut surface and up to the depth of $20 \mu \mathrm{m}$ increases several times compared to the microhardness before cutting because there are hard oxide phases like $\mathrm{NiO}$ and $\mathrm{Cu}_{2} \mathrm{O}$ metal oxides on the surface and fast solidification of alloy layer formed by flushing the d-ionized water (considering solidification speed is about a few microseconds) so that superficial layer of cut surface has higher microhardness than base piece.

(3) The cut surface with a thickness of $2 \mathrm{~mm}$ and a 10$20 \mu \mathrm{m}$ superficial layer formed on the surface (cutting is done by WEDM), and by taking into account the chemical analysis besides different mechanical and physical properties, this layer has a significant reversible strain percentage that it shows the poor effect of cutting on the shape memory characteristic of this alloy.

(4) By forming hard microlayer on the surface and because high hardness is preferable in Nitinol-60 alloy, machining by WEDM is the prior method because it has the ability of shape recovery while the surface hardness of Nitinol-60 increases.

\section{References}

[1] D. E. Hodgson, M. H. Wu, and R. J. Biermann, "Shape memory alloys," in Metals Handbook, vol. 2, pp. 897-890, 10th edition, 1990.

[2] M. W. M. van der Wijst, Shape Memory Alloys Featuring Nitinol, TU Eindhoven Faculteit der Werktuigbouwkunde Vakgroep WFW, Veldhoven, The Netherlands, 1992.

[3] E. Hornbogen, V. Mertinger, and D. Wurzel, "Microstructure and tensile properties of two binary NiTi-alloys," Scripta Materialia, vol. 44, no. 1, pp. 171-178, 2001.

[4] A. A. Khamei and K. Dehghani, "A study on the mechanical behavior and microstructural evolution of Ni60 wt\%-Ti40 wt\% (60Nitinol) intermetallic compound during hot deformation," Materials Chemistry and Physics, vol. 123, no. 1, pp. 269-277, 2010.

[5] C. DellaCorte, S. V. Pepper, R. Noebe, D. R. Hull, and G. Glennon, Intermetallic Nickel-Titanium Alloys for Oil-Lubricated Bearing Applications, NASA/TM-2009-215646, 2009.

[6] C. DellaCorte, "Nickel-Titanium alloys: corrosion proof alloys for space bearing components and mechanism applications," in Proceedings of the 40th Aerospace Mechanisms Symposium, NASA Kennedy Space Center, May 2010.

[7] C. Greiner, S. M. Oppenheimer, and D. C. Dunand, "High strength, low stiffness, porous NiTi with superelastic properties," Acta Biomaterialia, vol. 1, no. 6, pp. 705-716, 2005.

[8] B. Yuan, C. Y. Chung, and M. Zhu, "Microstructure and martensitic transformation behavior of porous NiTi shape memory alloy prepared by hot isostatic pressing processing," Materials Science and Engineering A, vol. 382, no. 1-2, pp. 181-187, 2004.

[9] A. A. Lotfi, S. Daneshmand, and S. Adib Nazari, "The effect of operational cutting parameters in the wire electro discharge machining (WEDM) on micro hardness of alloy surface layer," Journal of Advanced Design and Manufacturing Technology, vol. 2, no. 4, pp. 51-58, 2009.

[10] S. Kuriakose and M. S. Shunmugam, "Characteristics of wireelectro discharge machined $\mathrm{Ti}_{6} \mathrm{Al}_{4} \mathrm{~V}$ surface," Materials Letters, vol. 58, no. 17-18, pp. 2231-2237, 2004.

[11] K. Weinert and V. Petzoldt, "Machining of NiTi based shape memory alloys," Materials Science and Engineering A, vol. 378, no. 1-2, pp. 180-184, 2004.

[12] H. C. Lin, K. M. Lin, and Y. C. Chen, "Study on the machining characteristics of TiNi shape memory alloys," Journal of Materials Processing Technology, vol. 105, no. 3, pp. 327-332, 2000.

[13] W. Theisen and A. Schuermann, "Electro discharge machining of nickel-titanium shape memory alloys," Materials Science and Engineering A, vol. 378, no. 1-2, pp. 200-204, 2004.

[14] S. L. Chen, S. F. Hsieh, H. C. Lin, M. H. Lin, and J. S. Huang, "Electrical discharge machining of a NiAlFe ternary shape memory alloy," Journal of Alloys and Compounds, vol. 464, no. 1-2, pp. 446-451, 2008.

[15] J. A. Mc Geough, Advanced Methods of Machining, Springer, Chapman \& Hall, London, UK, 1988.

[16] E. C. Jameson, "Description and development of electrical discharge machining," in Electrical Discharge Machining, p. 16, SME, Dearborn, Mich, USA, 2001.

[17] K. H. Ho, S. T. Newman, S. Rahimifard, and R. D. Allen, "State of the art in wire electrical discharge machining (WEDM)," International Journal of Machine Tools and Manufacture, vol. 44, no. 12-13, pp. 1247-1259, 2004.

[18] C. Sommer and S. Sommer, Free-Complete EDM Handbook, Advance Pub, 2005.

[19] J. R. Davis, Metals Handbook Machining, vol. 16, ASM International, Novelty, Ohio, USA, 9th edition, 1989.

[20] N. Tosun, C. Cogun, and H. Pihtili, "The effect of cutting parameters on wire crater sizes in wire EDM," International Journal of Advanced Manufacturing Technology, vol. 21, no. 10-11, pp. 857-865, 2003.

[21] G. H. Dehghan and A. A. LotfiNeyestanak, Comparative Morphological Studies of Spark Eroded Surfaces on WEDM and SEDM, TICME, Tehran, Iran, 2005.

[22] ASTM Standard, Standard Specification for Wrought NickelTitanium Shape Memory Alloys for Medical Devices and Surgical Implants, Specification F2063-00, 2000.

[23] Y. Suzuki, K. Otsukaand, and C. M. Wayman, Fabrication of Shape Memory Alloys, Cambridge University Press, 1998.

[24] C. L. Chu, C. Y. Chung, P. H. Lin, and S. D. Wang, "Fabrication and properties of porous NiTi shape memory alloys for heavy load-bearing medical applications," Journal of Materials Processing Technology, vol. 169, no. 1, pp. 103-107, 2005. 

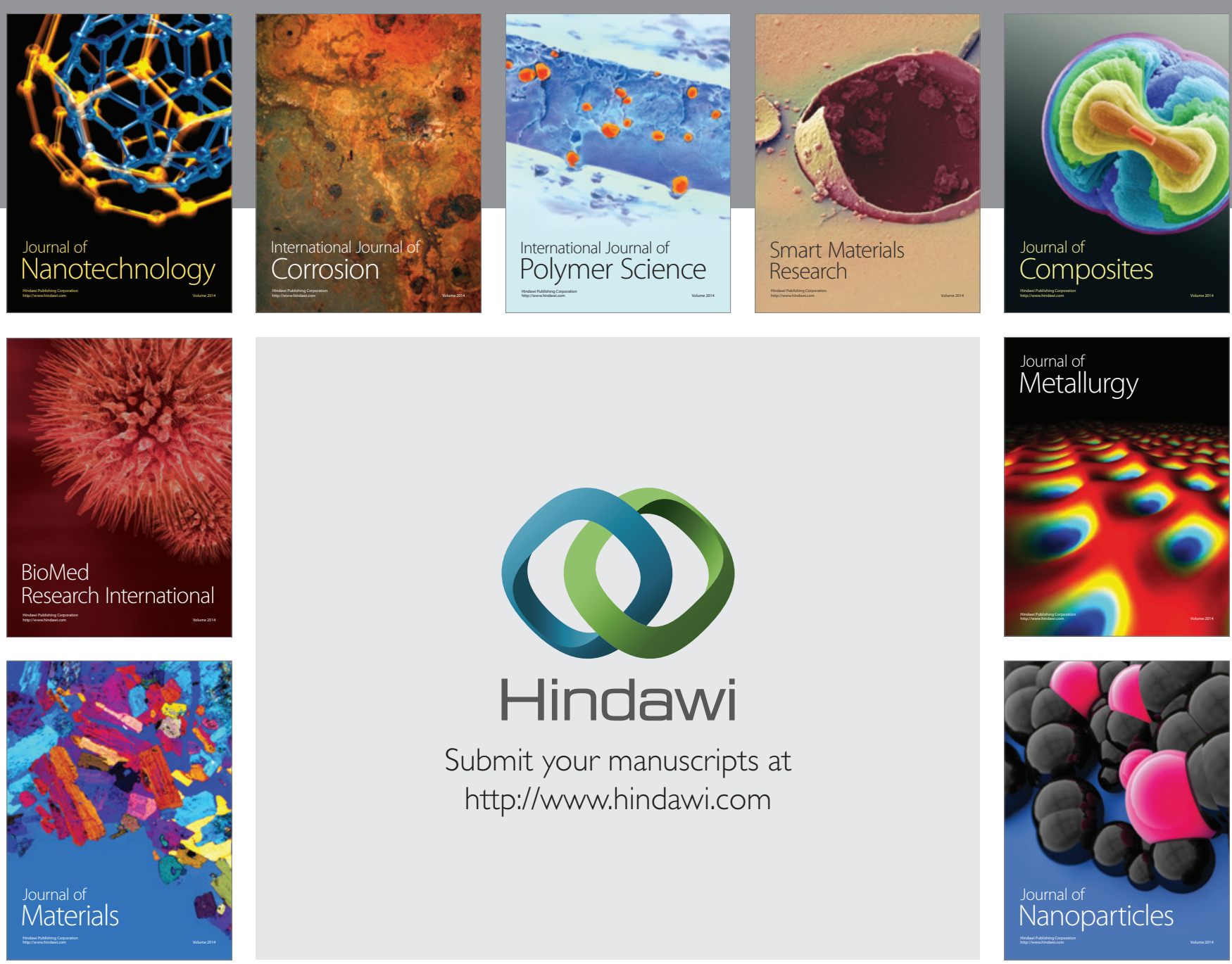

Submit your manuscripts at http://www.hindawi.com
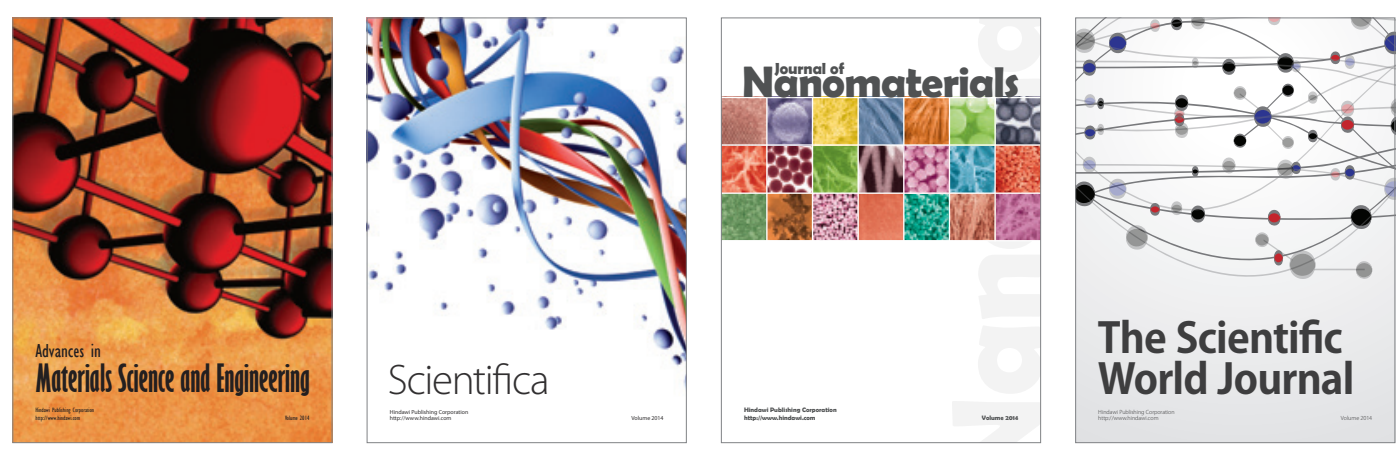

\section{The Scientific World Journal}
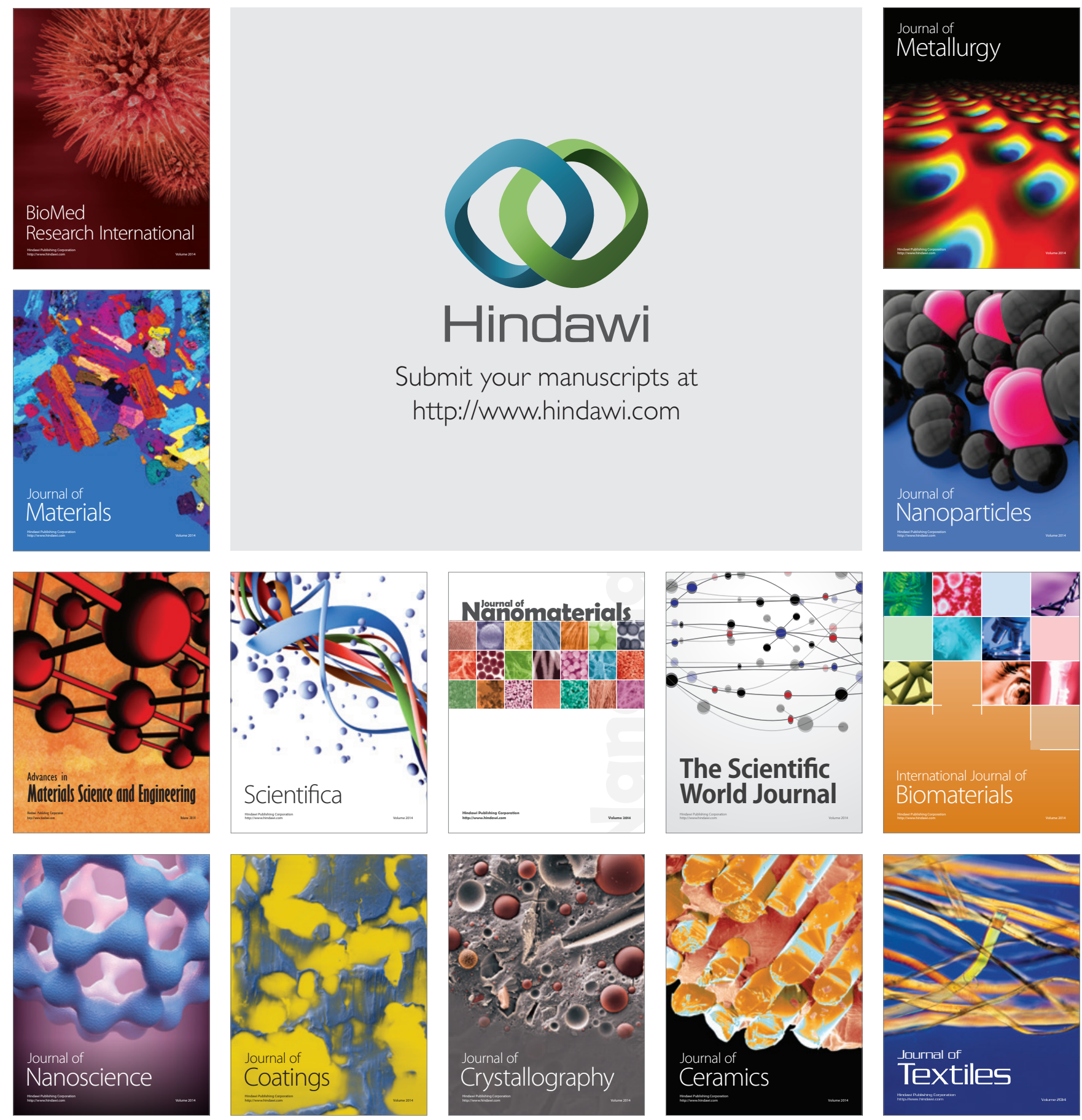